\title{
Outcome of surgery for type A aortic dissection - Twenty year evolution of a single surgeon practice
}

\author{
Ishtiaq A Rahman*; Manhar Khatri; Pradeep Narayan; Alan J Bryan \\ mary, Bristol, BS2 8HW, England, United Kingdom.

\section{*Corresponding Author(s): Ishtiaq Rahman} \\ Specialist Registrar Cardiac Surgery, The Bristol Heart \\ Institute, University Hospitals Bristol NHS Foundation \\ Trust, Bristol, BS2 8HW, England, United Kingdom \\ Tel: 0044-117-342-6576, Fax: 0044-117-342 5968 \\ Email: IshtiaqRahman@nhs.net
}

Department of Cardiac Surgery, The Bristol Heart Institute, University Hospitals Bristol NHS Foundation Trust, Bristol Royal Infir-

Received: May 23, 2018

Accepted: Aug 06, 2018

Published Online: Aug 10, 2018

Journal: International Journal of Innovative Surgery

Publisher: MedDocs Publishers LLC

Online edition: http://meddocsonline.org/

Copyright: (C) Rahman I (2018). This Article is distributed under the terms of Creative Commons Attribution 4.0 International License

Keywords: Thoracic surgery; Aortic diseases; Circulatory arrest; Deep hypothermia induced

\section{Abstract}

Background: This study investigated type A aortic dissection repair outcomes in a single surgical practice focusing on surgical, perfusion and anaesthetic techniques.

Methods: Prospectively collected Type A dissection surgery data over a twenty year single surgeon practice analysed. Operations grouped into ten year eras ( $A$ and $B$ ). Risk calculated using Euro score, Parsonnet and a validated Aortic system.

Results: Ten year study eras included 47 and 45 patients respectively. Era A patients were more likely (91\%) to present with good, and era B (35\%) moderate, left ventricular function. Incidence of arch replacement, composite root replacement and interposition graft was comparable. Circulatory arrest became less common (91\% vs. $82 \%$; $p=0.13$ ). Circulatory arrest, CPB and AXC times remained constant. Perfusion strategy shifted from femoral cannulation (89\% vs. $24 \%$; $p<0.01)$. Overall mortality was $13 \%$ and improved with time ( $17 \%$ vs. $9 \%$; $p=0.36)$. Composite end point of freedom of death, neurological injury and reoperation for bleeding remained similar (66\% vs. $69 \% ; p=0.36)$. Renal complications, tracheostomy, ICU and hospital stay did not alter.

Conclusion: Over twenty years in-hospital mortality dropped by almost $50 \%$. Small sample size hindered statistical evidence. Increased valve conservation, reduced incidence of composite root replacement, circulatory arrest and reoperation for bleeding are encouraging.

symptom onset, $[3,4]$. but reassuringly, early identification and timely surgery in AAD of the ascending aorta has been shown to be beneficial in this highly lethal condition by reducing early mortality from $55.9 \%$ to $26.6 \%$ [5]. Survival rates are $52-94 \%$ at one year and $45-85 \%$ at 5 years in type A patients [6].

Due to the nature of the disease, research in the form of randomised studies has proven difficult. It is now recognised that large registries such as the International Registry of Acute Aortic Dissection (IRAD)[5] and the German Registry for Acute Aortic tients suffer a mortality rate of 1-2\% per hour immediately after 
Dissection Type A (GERAADA) [7] offer the best prospect of providing information to guide treatment. Nevertheless, there is little information relating to outcomes within the practice of a single surgeon. Evidence exists in both General Surgery and Vascular Surgery that surgical experience does improve long term results $[8,9]$.

Some of the best published results have been achieved by the application of some of the simplest surgical principles $[10,11]$. In the UK, individual surgeons are likely to have limited first operator experience when starting their independent consultant level practice. Evidence exists to suggest that the higher the annual hospital thoracic aortic surgery volume the better the outcome [12]. Surgery for Type A aortic dissection has been described as 'conceptually simple but practically demanding' [13].

The goals of Type A AAD surgery are to save life by prevention of pericardial tamponade/rupture, to resect the primary entry tear, to correct or prevent any malperfusion and aortic valve regurgitation, and if possible to prevent late dissection-related complications in the proximal and downstream aorta [13].

To date the evidence suggests that surgical (30 day) and long term survival of aortic dissection patients has improved over time [14]. Those centres treating 19 or more cases of Type A dissection per year in the UK have achieved better outcomes, whilst measures such as the development and implementation of a multi-disciplinary team approach at specialised centres have been shown to have the potential to reduce operative mortality rates from $33.9 \%$ to $2.8 \%$ and improve 5 year survival rates from $55 \%$ to $85 \%(p<0.01)$ [15]. Naturally this has led to efforts to standardize and centralise care of these patients and reinforces the view that although surgical skill is important in relation to outcome the team approach and overall experience of a centre may be the dominant factors.

Other positive steps in surgical approach include the preferential use of an antegrade (right axillary or direct aortic cannulation) perfusion strategy to the true lumen over retrograde (femoral artery) during cardiopulmonary bypass. The right axillary approach is safe, with a low stroke rate $(11 \%)$ and high midterm survival ( $73 \pm 5 \%$ at 1 year; $64 \pm 6 \%$ at 3 years) [16] Antegrade perfusion improves survival at 10 years ( $71 \%$ vs. $51 \%$; $p<0.05$ ) whilst conversely retrograde perfusion has been shown to be an independent risk factor for late mortality in multivariate analysis $(p<0.01)[17]$. Ascending aortic cannulation is a safe alternative to femoral improving 30 day mortality rate ( $14 \%$ vs. $23 \% ; p=0.07$ ) and offers acceptable long term outcomes [18].

The development of effective surgical glues and pharmacologic therapies, such as recombinant activated factor VIla $[19,20]$ and aprotinin $[21]$ in concert with thromboelastography targeted therapy have reduced bleeding complications.

The wider management of these patients has also improved, particularly the understanding of cerebral perfusion techniques. Antegrade cerebral perfusion appears to offer the best strategy. In a study comparing the use of Deep Hypothermic Circulatory Arrest (DHCA) at $18^{\circ} \mathrm{C}$ supported by either retrograde (RCP) or Antegrade Cerebral perfusion (ACP) at $25^{\circ} \mathrm{C} 30$ day mortality was lowest in the ACP group (DHCA alone $26 \%$ vs. RCP $16 \%$ vs. ACP $13 \% ; p<0.05)$, as was permanent neurologic dysfunction (DHCA alone $23 \%$ vs. RCP $12 \%$ vs. ACP $12 \%$; p<0.05) [22].

Newer anaesthetic techniques have included using perioperative transoesophageal echocardiography, monitoring perfu- sion and aortic valve function and managing deep hypothermic circulatory arrest and pharmacologic adjuncts to neuroprotection [11].

There would therefore seem to be ample reason to hypothesise that the surgical treatment of patients with type A dissection has improved.

The principal aim of this observational study was to examine whether increased operator experience and evolution of surgical techniques in association with improvements in perfusion and perioperative care have improved clinical outcomes in the management of Type A AAD patients over a twenty year career of one surgeon with an increasing portfolio of aortic surgery. The authors acknowledge that the single surgeon model may be considered outdated by some and within our centre the transition to a multi-disciplinary approach to the management of Type A aortic dissection has now been fully implemented. However the change in approach has been relatively recent and merit in the investigation of the single surgeon model remains useful when reviewing practice over a 20 year period.

\section{Materials and methods}

Consecutive patients undergoing treatment for Type A aortic dissection by a single surgeon at the Bristol Heart Institute during the period from $12^{\text {th }}$ July 1993 to $11^{\text {th }}$ July 2013 were included. To analyse changes in outcome the experience was divided into two equal 10 year eras: $12^{\text {th }}$ July 1993 to $11^{\text {th }}$ July 2003 (study era A) and $12^{\text {th }}$ July 2003 to $11^{\text {th }}$ July 2013 (study era B).

Demographics, preoperative, intraoperative and postoperative data for procedures before April 1996 were abstracted from the operation notes. From April 1996 data was collected prospectively on all patients undergoing cardiac surgery and entered into a database (Patient Analysis and Tracking System (Dendrite Clinical Systems Inc, London, UK)), deaths after hospital discharge were identified from mortality data provided by the National Health Service Strategic Tracing Service. All patients were successfully matched to the National Health Service Strategic Tracing Service database.

The validated and specialised aortic score devised by Mehta et al. [23] was used to assess risk in addition to both standard Parsonnet and Euroscore systems. These two systems were used consistently throughout the time period.

Arch replacement was defined as operations requiring two or more distal anastomoses, one to the distal aorta and one to one or more aortic arch branches. Thus, if the under surface of the aortic arch was replaced (hemi-arch) with a single distal anastomosis, it was considered to be an ascending aortic operation only. Renal complications included need for frusemide infusion, renal impairment requiring haemofiltration or dialysis. Definitions with respect to operative priority, premorbid conditions and postoperative complications are those defined by the National Adult Cardiac Surgical Database and accepted by the Society for Cardiothoracic Surgeons in Great Britain and Ireland (available at www.scts.org).

The mainstay of surgical treatment was interposition graft replacement of the ascending aorta with valve conservation where possible, but composite root replacement was performed for connective tissue disorders or patients with dilatation or extensive dissection within the sinuses of Valsalva.

During the study period, a range of approaches and develop- 
ments occurred continually, often without being adopted at a single time point. With respect to the surgical techniques in the second era, more effective biological glues (Bioglue; Cryolife Europa Ltd, Guildford, UK) replaced the Gelatin-Resorcin-Formulin (GRF), and aggressive resection of the primary intimal tear with the use of an open distal anastomotic technique has become routine. The tear in the ascending aorta was replaced to the level of the innominate artery. Spiral tears extending along the under surface of the arch were treated with a bevelled distal anastomosis (hemiarch replacements). In study era B, more resections were performed with a hemiarch replacement. Complete aortic arch replacement was performed only for tears within the aortic arch.

From a perfusion perspective, routine femoral artery cannulation throughout was superseded by the adoption of antegrade reperfusion on completion of the anastomosis via the side arm of the Ante-Flo (Gelweave; Vascutek Itd, Renfrewshire) graft conduit, and more recently axillary artery cannulation has been predominantly used. The right axillary artery was preferentially used unless there was haemodynamic instability, right upper limb malperfusion, tamponade or previous surgery in the axilla.

Additional cerebral protection during deep hypothermic circulatory arrest (cooling to $18^{\circ} \mathrm{C}$ ) has changed from widespread use of retrograde cerebral perfusion to circulatory arrest alone to the use of antegrade cerebral perfusion via the axillary artery (separate line $10 \mathrm{ml} / \mathrm{kg} / \mathrm{min}$ ) or endoluminally (left and/or right carotid artery).

With respect to anaesthetic techniques, intraoperative transoesophageal echocardiography has been routine in study era B. Aprotinin was used throughout the study period until it was withdrawn, and cell savers were used more commonly, latterly. Only toward the end of study era B was recombinant factor VIla used to achieve haemostasis in problematic cases. Thromboelastography has been used exclusively in the latter half (study era B) to guide appropriate use of other blood products.

Data was analysed with statistical package (SPSS 15.0, Chicago, III). Categoric or ordinal data were compared by using $\chi 2$ tests or Kendall tau b, respectively. Continuous data are presented as mean \pm standard deviation. Normally distributed data were compared using independent two-sided t tests. Skewed data were either logarithmically transformed or analysed nonparametrically (Mann-Whitney U test).

\section{Results}

A total of 92 consecutive patients were included over a 20 year period. In the former 10 year period ( $12^{\text {th }}$ July 1993 to $11^{\text {th }}$ July 2003; study era A) there was 47 patients and in the latter period ( $12^{\text {th }}$ July 2003 to $11^{\text {th }}$ July 2013; study era B) 45 patients were included.

Both study eras were comparable for baseline demographics. (Table 1) Difference was noted in the percentage of patients with good, moderate and poor left ventricular function; proportionally fewer patients had good function in the latter era. There were matched number of patients with the Marfan syndrome in both era ( $13 \%$ vs. $0 \% ; p=0.17)$.

Details of the surgical procedure are summarized (Table 2). Similar numbers of patients underwent arch replacement, composite root replacement and interposition graft over the two eras. There was a suggestion less patients underwent circulatory arrest in the second era ( $91 \%$ vs. $82 \% ; p=0.13$ ) however the time on circulatory arrest of those who received it was comparable between the groups. The CPB and AXC times remained static. There was no difference in the rate of concomitant procedures (mitral valve/coronary surgery). In the second era perfusion strategy shifted away from femoral cannulation (89\% vs. 24\%; $p<0.01)$.

There were a total of 12 in-hospital deaths over the twenty year period (13\%) and mortality was lower but did not reach statistical significance in the second era ( $17 \%$ vs. $9 \%$; $p=0.36)$, (Table 3) but the composite endpoint of freedom of death, neurological injury and reoperation for bleeding remained similar (66\% vs. $69 \% ; p=0.36$ ). Renal complication and tracheostomy incidence along with length of ICU and hospital stay did not alter.

\section{Discussion}

This study has shown that in a single surgeon practice, over a twenty year period in hospital mortality reduced from $17 \%$ to 9\% following Type A dissection repair. Taken in an international context the twenty year mortality of $13 \%$ is significantly lower than the real world data published in IRAD of $25.1 \%$ [24].

Although the results do not match the best published results, $[10,11]$ caution has been advised when considering small single surgeon series' with low mortalities in providing a likely potential outcome for a patient with type A dissection [25]. Studies collecting outcome from large numbers of patients as registry data, such as IRAD, probably reflect more accurately potential outcome.

The data from this study suggests that the hypothesis that increasing surgical experience improves patient outcome over his/her career is a realistic one. The purported benefit of technological advances in anaesthetic, surgical and perfusion techniques have not been individually analysed to assess impact on outcome in this investigation and we recommend this to be the focus of future research. As these factors have been implemented at differing times and in piecemeal fashion this adds to the challenge of assigning individual benefit in outcome. This evidence adds substance to the arguments presented by the proponents of specialised centres housing expert aortic surgeons to deliver prompt care, in large volumes to those presenting for emergency type A dissection repair. At present centralised care of thoracic aortic surgical patients is patchy and inconsistently delivered within the UK.

In a twenty year career of ninety-two consecutive patients an in-hospital mortality of $13 \%$ was achieved, better than those in large series' reported in the literature. It is important to be mindful though of the nature and devastating presentations of this condition and the end-organ ischaemia that results from cerebral, visceral or coronary malperfusion. The surgical community must continue to strive to further improve outcomes.

As this study is limited by its small size, observational approach, risk of publication bias and confounding factors such as the effects of time and improvements in anaesthesia and perioperative care it becomes difficult to ascertain the effects of improvements attributable to surgeon expertise and technical advances. The real strengths lie in its use of prospectively collected data and focus on a single surgeon experience over a prolonged period. 
In summary this study has demonstrated that over a 20 year period a surgeon can develop significant measurable expertise, in combination with technological progress in anaesthesia, surgical techniques and perfusion strategy, to reduce observed mortality rates by $50 \%$. There was no observed improvement in neurological events but conservation of the aortic valve, reduc-

Tables

Table 1: Baseline demographics

\begin{tabular}{|c|c|c|c|}
\hline Study era & A & B & $\mathbf{p}$ \\
\hline Number of patients (n=; \%) & $47(51)$ & $45(49)$ & - \\
\hline Age (mean $\pm S D)$ (years) & $58.0 \pm 15.1$ & $61.2 \pm 13.9$ & 0.39 \\
\hline Mehta Score (mean $\pm S D)$ & $2.6 \pm 1.3$ & $2.2 \pm 1.0$ & 0.75 \\
\hline Mehta Score (median(IQR1-IQR3)) & $2.8(1.6-3.7)$ & $2.3(1.5-2.8)$ & 0.75 \\
\hline Age $>70$ yrs $(n=; \%)$ & $14(30)$ & $12(27)$ & 0.82 \\
\hline Female sex $(n=; \%)$ & $13(28)$ & $16(36)$ & 0.5 \\
\hline Abrupt onset pain on presentation $(n=; \%)$ & $37(79)$ & $38(84)$ & 0.97 \\
\hline Abnormal ECG on presentation ( $n=; \%)$ & $21(47)$ & $23(51)$ & 0.83 \\
\hline Any pulse deficit on presentation ( $n=; \%)$ & $12(26)$ & $9(20)$ & 0.46 \\
\hline Kidney failure preop (n=; \%) & $16(34)$ & $10(22)$ & 0.27 \\
\hline Hypotension/shock/tamponade on presentation ( $n=; \%)$ & $17(36)$ & $12(27)$ & 0.26 \\
\hline Parsonnet Score (mean \pm SD) & $28.9 \pm 8.8$ & $28.0 \pm 15.0$ & 0.39 \\
\hline Parsonnet Score (median(IQR1-IQR3)) & $30(23.5-31.8)$ & $24(23-28)$ & 0.39 \\
\hline Euroscore (mean $\pm S D)$ & $9.3 \pm 2.7$ & $10.4 \pm 2.8$ & 0.14 \\
\hline Euroscore (median(IQR1-IQR3)) & $9(7-11)$ & $10(8-12)$ & 0.14 \\
\hline Marfan syndrome (n=; \%) & $6(13)$ & $0(0)$ & 0.17 \\
\hline Hypertension (n=; \%) & $22(47)$ & $22(49)$ & 0.52 \\
\hline Peripheral vascular disease $(n=; \%)$ & $6(13)$ & $3(7)$ & 0.73 \\
\hline LV function $-\operatorname{good}(n=; \%)$ & $43(91)$ & $4(8)$ & \\
\hline - moderate $(n=; \%)$ & $3(6)$ & $16(35)$ & - \\
\hline$-\operatorname{poor}(n=; \%)$ & $1(2)$ & $2(4)$ & \\
\hline Redo (n=; \%) & $2(4)$ & $5(11)$ & 0.23 \\
\hline
\end{tabular}

Table 2: Operative data

\begin{tabular}{|c|c|c|c|}
\hline Study era & A & B & $\mathbf{p}$ \\
\hline Number of patients ( $n=; \%)$ & $47(51)$ & $45(49)$ & - \\
\hline Arch replacement $(n=; \%)$ & $6(13)$ & $7(16)$ & 0.54 \\
\hline Composite root replacement ( $\mathrm{n}=; \%)$ & $16(34)$ & $10(22)$ & 0.26 \\
\hline Interposition graft $(\mathrm{n}=; \%)$ & $28(60)$ & $36(80)$ & 0.42 \\
\hline AVR - $0=N(n=; \%)$ & $13(28)$ & $27(60)$ & \multirow{3}{*}{-} \\
\hline$-1=Y(n=; \%)$ & $17(36)$ & $7(16)$ & \\
\hline$-2=S(n=; \%)$ & $17(36)$ & $3(7)$ & \\
\hline Circulatory arrest $(n=; \%)$ & $43(91)$ & $37(82)$ & 0.13 \\
\hline Circulatory arrest time (mins) (mean \pm SD) & $35 \pm 11$ & $45 \pm 46$ & 0.14 \\
\hline
\end{tabular}

tion in need for both composite root replacement and circulatory arrest along with a decline in reoperation for bleeding are encouraging signs of significant progress in the management of this condition. Statistically convincing evidence of improvements in outcome have been hampered by the relatively small sample size. Outcomes in the current era conform to contemporary standards. 


\begin{tabular}{|c|c|c|c|}
\hline CPB time (mins) (mean $\pm S D$ ) & $167 \pm 46$ & $182 \pm 42$ & 0.32 \\
\hline AXC time (mins) (mean $\pm S D$ ) & $91 \pm 38$ & $100 \pm 39$ & 0.25 \\
\hline Mitral valve surgery $(n=; \%)$ & $1(2)$ & $0(0)$ & 1.00 \\
\hline $\operatorname{CABG}(n=; \%)$ & $7(15)$ & $7(16)$ & 0.59 \\
\hline Number of grafts (mean $\pm S D$ ) & $0.3 \pm 0.7$ & $0.3 \pm 0.7$ & 0.55 \\
\hline Femoral cannulation $(n=; \%)$ & $42(89)$ & $11(24)$ & $<0.01$ \\
\hline
\end{tabular}

Table 3: In-hospital outcomes

\begin{tabular}{|l|c|c|c|}
\hline Study era & A & B & p \\
\hline Number of patients (n=; \%) & $47(51)$ & $45(49)$ & 0.36 \\
\hline In-hospital death (n=; \%) & $8(17)$ & $4(9)$ & 0.29 \\
\hline New neurological events - transient (n=; \%) & $2(4)$ & $0(0)$ & 1.00 \\
\hline - permanent (n=; \%) & $4(9)$ & $6(13)$ & 0.36 \\
\hline Reoperation for bleeding (n=; \%) & $5(11)$ & $4(9)$ & 0.15 \\
\hline Renal complications (n=; \%) & $2(4)$ & $3(7)$ & 0.64 \\
\hline Tracheostomy (n=; \%) & $4(9)$ & $6(13)$ & 0.76 \\
\hline ICU stay (median(IQR 1 - IQR3)) & $3(2-5)$ & $4(2-5)$ & 0.36 \\
\hline Hospital stay (median(IQR 1 - IQR3)) & $12(9-16)$ & $14(8-20)$ & $31(69)$ \\
\hline $\begin{array}{l}\text { Composite endpoint (freedom death/neuro } \\
\text { injury /reop bleed) (n=; \%) }\end{array}$ & $31(66)$ & & \\
\hline
\end{tabular}

\section{References}

1. Green RG, Kron IL. Aortic dissection. In: Cohn HL, Edmunds HL Jr., eds. Cardiac Surgery in the Adult. New York: McGraw Hill Companies. 2003;1097.

2. Butler J, Ormerod OJM, Giannpoulos N, Pillai R, Westaby S. Quaterly Journal of Medicine. 1991; 79: 391-396.

3. Meszaros I, Morocz J, Szlavi J, Schmidt J, Tornoci L, Nagy L, Szep L. Epidemiology and clinicopathology of aortic dissection. Chest. 2000; 117: 1271-1278.

4. Tsai TT, Nienaber CA, Eagle KA. Acute aortic syndromes. Circulation. 2005; 112: 3802-3813.

5. Hagan PG, Nienaber CA, Isselbacher EM, Bruckman D, Karavite DJ, Russman PL et al. The International Registry of Acute Aortic Dissection (IRAD): New insights into an old disease. JAMA. 2000; 283: 897-903.

6. Tsai TT, Evangelista A, Nienaber CA, Trimarchi S, Sechtem U, Fattori R, et al. International Registry of Acute Aortic Dissection (IRAD). Long-term survival in patients presenting with type A acute aortic dissection: Insights from the International Registry of Acute Aortic Dissection (IRAD). Circulation. 2006; 114: I350-6.

7. Conzelmann LO, Krüger T, Hoffmann I, Rylski B, Easo J, Oezkur Met al. Teilnehmenden GERAADA-Zentren. [German Registry for Acute Aortic Dissection Type A (GERAADA): initial results]. Herz. 2011; 36: 513-24.

8. Luostarinen ME, Isolauri JO. Surgical experience improves the long-term results of Nissen fundoplication. Scand J Gastroenterol. 1999; 34: 117-20.

9. Kantonen I, Lepantalo M, Salenius JP, Matzke S, Luther M, Ylon- en K. Influence of surgical experience on the results of carotid surgery. The Finnvasc Study Group. Eur J Vasc Endovasc Surg. 1998; 15920: 155-160

10. Westaby S, Saito S, Katsumata T. Acute type A dissection: Conservative methods provide consistently low mortality. Ann Thorac Surg. 2002; 73: 707-13.

11. Bavaria JE, Brinster DR, Gorman RC, Woo YJ, Gleason T, Pochettino A. Advances in the treatment of acute type A dissection: An integrated approach. Ann Thorac Surg. 2002; 74: S1848-52

120. MiyataH, Motomura N, Ueda Y, Tsukihara H, Tabayashi K, Takamoto $\mathrm{S}$. Toward quality improvement of thoracic aortic surgery: estimating volume-outcome effect from nationwide survey. Eur J CardiothoracSurg. 2009; 36: 517-523.

13. Bonser RS, Ranasinghe AM, Loubani M, Evans JD, Thalji NM, Bachet JE, et al. Evidence, lack of evidence, controversy, and debate in the provision and performance of the surgery of acute type A aortic dissection. J Am CollCardiol. 201; 58: 2455-74.

14. Olsson C1, Thelin S, Ståhle E, Ekbom A, Granath F.Thoracic aortic aneurysm and dissection: Increasing prevalence and improved outcomes reported in a nationwide population-based study of more than 14,000 cases from 1987 to 2002. Circulation. 2006; 114: 2611-8.

15. Andersen ND1, Ganapathi AM, Hanna JM, Williams JB, Gaca JG, Hughes GC. Outcomes of acute type a dissection repair before and after implementation of a multidisciplinary thoracic aortic surgery program. J Am Coll Cardiol. 2014; 63:1796-803.

16. Wong DR, Coselli JS, Palmero L, Bozinovski J, Carter SA, Murariu $D$, et al. Axillary artery cannulation in surgery for acute or subacute ascending aortic dissections.AnnThorac Surg. 2010; 90: 731-7. 
17. Etz CD, von Aspern K, da Rocha E Silva J, Girrbach FF, Leontyev $\mathrm{S}$, Luehr $\mathrm{M}$, et al. Impact of perfusion strategy on outcome after repair for acute type a aortic dissection.AnnThorac Surg. 2014; 97: 78-85.

18. Kamiya H, Kallenbach $\mathrm{K}$, Halmer D, Ozsöz M, Ilg K, Lichtenberg $A$, et al. Comparison of ascending aorta versus femoral artery cannulation for acute aortic dissection type A. Circulation. 2009; 120: S282-6.

19. Tritapepe L, Santis VD, Vitale D, Nencini C, Pellegrini F, Landoni GL. Recombinant activated factor VII for refractory bleeding after acute aortic dissection surgery: A propensity score analysis. Crit Care Med. 2007; 35: 1685-90.

20. Raivio $\mathrm{P}$, Suojaranta-Ylinen $\mathrm{R}$, Kuitunen $\mathrm{AH}$. Recombinat factor $\mathrm{VIla}$ in the treatment of postoperative haemorrhage after cardiac surgery. Ann Thorac Surg. 2005; 80: 66-71.

21. Sedrkayan A, Wu, Sedrakayan G, Diener West M, Tanquilli M, Elefteriades J. Aprotinin use in thoracic aortic surgery; safety and outcomes. J ThoracCardiovasc Surg. 2006; 132: 909-17.

22. Wiedemann D, Kocher A, Dorfmeister M, Vadehra A, Mahr S, Laufer $\mathrm{G}$, et al. Effect of cerebral protection strategy on outcome of patients with Stanford type Aaortic dissection. JThorac Cardiovasc Surg. 2013; 146: 647-55.
23. Mehta RH, Suzuki T, Hagan PG, Bossone E, Gilon D, Llovet A, et al. International Registry of Acute Aortic Dissection (IRAD) Investigators. Predicting death in patients with acute type a aortic dissection. Circulation. 2002; 105: 200-6.

24. Trimarchi S, Nienaber CA, Rampoldi V, Myrmel T, Suzuki T, Mehta $\mathrm{RH}$, Bossone E, Cooper JV, Smith DE, Menicanti L, Frigiola A, Oh JK, Deeb MG, Isselbacher EM, Eagle KA; International Registry of Acute Aortic Dissection Investigators. Contemporary results of surgery in acute type Aaorticdissection: The International Registry of Acute AorticDissection experience. J Thorac Cardiovasc Surg. 2005; 129: 112-22.

25. Bachet J. Acute Type A aortic dissection: can we dramatically reduce the surgical mortality. Ann Thorac Surg. 2002; 73: 701-3. 